\title{
RECRUITMENT AND RETENTION ISSUES FOR NEPAL'S GENERAL PRACTITIONERS
}

Hayes B*, Gupta $S^{*}$

\section{ABSTRACT}

The Medical Doctorate in General Practice (MDGP) began in 1982 with the aim of enabling doctors to provide comprehensive and effective management of common health problems encountered in rural Nepal where most of the population lives. This study, through personal questionnaires and interviews of Thirtynine of the Forty-six graduates to date, examines issues of practice location. Place of growing up appears significant in determining location of work. Health assistant background and undergraduate rural exposure appear non- significant. Lack of support staff and facilities are the greatest difficulties working in rural areas. Government policy, particularly frequent transfers and lack of clear career path and family factors, particularly children's education are major issues. Lack of specialist support, lifestyle issues and Continuing Medical Education appear non-significant. With this information, a selective admissions policy should be strongly considered. Greater cooperation with government and INGOs to encourage, place and appropriately use the operative and community skills of MDGPs is needed, especially in more remote areas where there is currently no viable private practice.

Key Words: Recruitment, Retention, Nepal, Practice Location, Selective Admissions.

\section{INTRODUCTION}

The Medical Doctorate in General Practice (MDGP) begun in 1982 as an initiative of the Tribhuvan University and the University of Calgary, Canada, has been the one postgraduate programme specifically seeking to address the rural doctor shortage by training doctors for district hospitals. In the light of Nepal's shortage of rural doctors to address the health needs of this country, it is essential that a study of factors affecting a doctor's decision concerning practice location be done.

Studies from developed countries notably USA, Canada and Australia suggest a number of significant factors. The doctor's background especially growing up in rural area has been found to be the most important independent predictor of rural practice..$^{1-3}$ Other factors suggested and studied have been exposure to rural practice during medical training both in medical school ${ }^{4,5}$ and residency, ${ }^{6,7}$ personal intention and motivation $^{1,8,9}$ and various financial, professional and lifestyle issues. ${ }^{10}$ There appear to be different factors in retention (1) income and workload, ${ }^{1,11}$ sense of preparedness for small town living and rural practice ${ }^{6}$ with the hypothesis that improved preparation would enhance recruitment and retention, ${ }^{6,12}$ professional satisfaction, ${ }^{11}$ family factors like spouse career opportunities and children's education ${ }^{8}$ and community influences..$^{13}$

* Patan Hospital, Kathmandu, Nepal.

** TU Teaching Hospital, Maharajgunj, Kathmandu, Nepal

Address for correspondence : Dr. Bruce Hayes

Patan Hospital, Patan

C/o United Mission to Nepal, P.O.Box: 126, Kathmandu, Nepal

Email: blhayes@cms.org.au 
In the 1994 evaluation as part of a Process Evaluation of the Nepal Health Development Project, ${ }^{14}$ it was found that MDGP residents were generally willing to serve in districts if certain basic criteria were met - Operating theatre with minimal support staff, residential facilities, available schooling, assurance of future postings in less remote areas, equitable HMG policies for posting and transfer and opportunities for private practice.

\section{METHODOLOGY}

This study was done by mailing or hand delivering a questionnaire to the 44 graduates resident in Nepal between February and June 2001. Pre-testing was done with graduates working in the Department of General Practice at IOM. If there was no response, another questionnaire copy was given at a personal meeting, was electronically mailed or a second mailing was done.

Information was collected on sex, age, marital state, number of children, number of years in practice (both medical and MDGP), doctor's birthplace, place of growing up, place of schooling, previous health experience, exposure to rural practice in undergraduate course, and spouse's hometown and educational training. The 2 outcome variables of interest were the types of community where first practiced and type of community of current practice. Information about work habits was also obtained.

Because of the small numbers for statistical analysis, 2 categories for each variable were made. Age, number of children and number of years of practice were re-categorized as to above or below the median of each variable. Places of birth and growing up were classified as large urban $(>100,000$ population) or rural. Places of work were also classified in this way and whether within or outside the Kathmandu Valley since this is the major urban area of Nepal. According to the rural/urban classification of the Human Resource Department within the Ministry of Health, most areas where MDGPs could work (especially the district hospitals of Nepal) are classified as urban because they are the district centres. Thus, this classification was less useful in distinguishing types of places of work. Since a number of spouses were from India this classification was also less useful for places of birth and growing up. Spouse training was categorized as professional/ health worker/graduate and other. The data results were compiled in SPSS programme. Bivariate analysis with Fisher's exact test was used to determine associations between the independent variables and the outcome variables. Because of the small numbers multivariate analysis was not felt to add much to the analysis.
Personal semi-structured interviews with graduates were done to clarify demographic information and exploration of hindrances to working in rural areas were also explored. These were in their place of work or in Kathmandu and by one group discussion of graduates at the Nepal Medical Association Conference in March 2001. With consent this interview was taped verbatim and later reviewed. All interviews were carried out in English by the author. Major themes identified were grouped together.

\section{RESULTS}

Contact was made with 39 of the 44 graduates living in Nepal. One graduate had died and one was in Brunei with the British Gurkhas. The 5 non-respondents were all out of Kathmandu Two were in Dhangadhi in Seti Government Zonal Hospital, one was in Ilam district with an NGO, Scalpel and government, one was in Dang in the government hospital and one was in Rajbiraj at the Zonal hospital.

Of these 39, 4 had personal interviews but did not return their questionnaires and 5 returned questionnaires but were not met personally leading to deficiencies in some results.

\section{FACTORS IN LOCATION OF WORK}

The bivariate analysis is shown in Table 1 as a correlation matrix.

Home, birthplace and schooling strongly correlated so were not studied separately. The 2 independent variables are places of first practice and current practice. The other variables are age, number of children, years of practice, years of Practice as MDGP, place of growing up, previous work experience, rural undergraduate exposure, place where spouse grew up and spouse's training.

$>$ The strong association between age $(>=43$ and $<43)$, Years of practice both medical $(<=12$ and $>12)$ and GP $(<=5$ and $>5)$, and the phase of the programme (Phases 1 and 2 vs Phase 3 ) is understandable as they are essentially conveying the same information (i.e. collinearity).

$>$ The younger doctors (and also, less time in practice and those in Phase 3) were more likely to have a Health Assistant (HA) background and had undergraduate rural exposure. In fact all Phase 1 and 2 doctors had a science background. This probably reflects the availability of training. The strong association between HA background and UG rural exposure probably is due to the above relationships. 
$>$ There was an association between spouses growing up in large urban centres and being more educated (a professional/graduate/health worker) probably reflecting opportunity.

$>$ There was an association between the doctor's and spouse's place of growing up (rural and rural) which may also reflect opportunity for meeting/arranging marriage.

$>$ There is a strong association between the 2 dependent variables indicating little movement of doctors. Of those outside Kathmandu Valley (or large urban setting), only 1 started his MDGP career in Kathmandu at a private hospital for 1 year before setting up a private clinic in his home district. One other doctor also had a brief time in Kathmandu while waiting for a job outside the Valley. Of those currently working in Kathmandu, only 2 (including the only female graduate) started outside the Kathmandu Valley working in government hospitals and had both moved to Nepal Medical College. One doctor in Kathmandu started in Kathmandu, went outside and had returned to Bir Hospital in Government service.

For place of first practice whether in or out of the Kathmandu Valley (or large urban versus rural which was the same result), the only factor which reached statistical significance $(\mathrm{p}<0.05)$ was the phase of the programme in which the graduate trained. Those trained in phase 3 are more likely to work outside the Kathmandu Valley (21/29) than those in Phases 1 and 2 (3/ 11) (Fisher's 2 tail exact test 0.014).

For current place of practice whether in or out of Kathmandu Valley, the following reached statistical significance -

- Place of growing up - more likely to be out of Kathmandu (and in rural area) if rural than large urban (Fisher's exact 2 tail 0.022 and 0.050 ).

- Spouse place of growing up - more likely to be out of Kathmandu (and in rural area) if rural than large urban (Fisher's exact 2 tail 0.082 and 0.037).

- Number of years as MDGP - more likely to be out of Kathmandu (and in rural area) if less than 5 years (Fisher's exact 2 tail 0.007 and 0.015 )

- Phase of Programme - more likely to be out of Kathmandu (and in rural area) if from Phase $3(25 / 33)$ than Phases 1 and $2(3 / 11)$ (Fisher's exact 2 tail 0.009 and 0.012)

The first 2 factors probably have some degree of collinearity though may be independent factors (and so confounders) but the latter 2 are definitely collinear. There is no association between place of growing up or any of the variables of age or length of practice suggesting these are independent effects on place of work. 